\title{
Review Article \\ GDF-15 as a Target and Biomarker for Diabetes and Cardiovascular Diseases: A Translational Prospective
}

\author{
Ramu Adela and Sanjay K. Banerjee \\ Drug Discovery Research Center, Translational Health Science and Technology Institute (THSTI), \\ Faridabad, Haryana 122014, India \\ Correspondence should be addressed to Sanjay K. Banerjee; skbanerjee@thsti.res.in
}

Received 11 December 2014; Revised 19 January 2015; Accepted 20 January 2015

Academic Editor: Joseph Fomusi Ndisang

Copyright (C) 2015 R. Adela and S. K. Banerjee. This is an open access article distributed under the Creative Commons Attribution License, which permits unrestricted use, distribution, and reproduction in any medium, provided the original work is properly cited.

\begin{abstract}
Growth differentiation factor-15 (GDF-15) is a stress responsive cytokine. It is highly expressed in cardiomyocytes, adipocytes, macrophages, endothelial cells, and vascular smooth muscle cells in normal and pathological condition. GDF-15 increases during tissue injury and inflammatory states and is associated with cardiometabolic risk. Increased GDF-15 levels are associated with cardiovascular diseases such as hypertrophy, heart failure, atherosclerosis, endothelial dysfunction, obesity, insulin resistance, diabetes, and chronic kidney diseases in diabetes. Increased GDF-15 level is linked with the progression and prognosis of the disease condition. Age, smoking, and environmental factors are other risk factors that may increase GDF-15 level. Most of the scientific studies reported that GDF-15 plays a protective role in different tissues. However, few reports show that the deficiency of GDF-15 is beneficial against vascular injury and inflammation. GDF-15 protects heart, adipose tissue, and endothelial cells by inhibiting JNK (c-Jun N-terminal kinase), Bad (Bcl-2-associated death promoter), and EGFR (epidermal growth factor receptor) and activating Smad, eNOS, PI3K, and AKT signaling pathways. The present review describes the different animal and clinical studies and patent updates of GDF-15 in diabetes and cardiovascular diseases. It is a challenge for the scientific community to use GDF-15 information for patient monitoring, clinical decision-making, and replacement of current treatment strategies for diabetic and cardiovascular diseases.
\end{abstract}

\section{Introduction}

Prevalence of diabetes is reaching epidemic proportions in young people due to increase in life expectancy, sedentary life style, and obesity. Adults with diabetes and obesity are more prone to cardiovascular complications (World health statistics 2014). As per the International Diabetic Federation (IDF) diabetes atlas (Sixth edition 2013), the number of people with diabetes is 382 million and it is going to rise to 592 million by 2035. Global burden of diabetes is huge and 548 billion dollars was spent in 2013. In India, approximately 65.1 million people are with diabetes [1]. The prevalence, incidence, and mortality of cardio vascular diseases are 28 -fold higher in persons having diabetes than those without diabetes [2].
Diabetes is characterized by high glucose level in blood due to either less insulin secretion from pancreas or developing insulin resistance in skeletal muscle. Diabetes is categorized into many types; however, two major types of diabetes are type 1 diabetes (T1DM) and type 2 diabetes (T2DM). T1DM is an autoimmune disease and result of autoimmune destruction of $\beta$ cells. Thus patients with T1DM are not able to secrete sufficient insulin in blood or totally lose insulin secretary capacity. T2DM is the commonest form and it is characterized by insulin resistance mostly in skeletal muscle and deficiency of insulin release at end stage. In general, T2DM causes elevation of blood glucose level and other components of metabolic syndrome. Parameters of metabolic syndrome are elevated blood pressure, elevated triglycerides, reduced high density lipoprotein levels, and 
abdominal obesity. An increase in adipose tissue (abdomen obesity) results in elevation of adipokines, that is, free fatty acids (FFA), tumor necrosis factor (TNF- $\alpha$ ), C-reactive protein (CRP), interleukin-6 (IL-6), plasminogen activator inhibitor-1 (PAI-1), adiponectin, and leptin. Adipocytokines integrate the endocrine, autocrine, paracrine signals to mediate the insulin sensitivity, oxidative stress, energy metabolism, blood coagulation, and inflammatory responses. Elevated levels of FFA induce insulin resistance and increase fibrinogen and PAI-1. In the long run, high FFA and glucose together impair beta cell function through lipotoxicity and glucotoxicity and develop macro- and microvascular complications [3, 4]. Recently GDF-15 was identified as one of the important plasma markers, which correlates with cardiometabolic syndrome.

Growth differentiation factor-15 (GDF-15) is a member of the transforming growth factor- $\beta$ (TGF- $\beta$ )/bone morphogenetic protein (BMP) super family. GDF-15 is also known as macrophage inhibiting cytokine 1 (MIC-1), placental transformation growth factor (PTGF- $\beta$ ), prostate derived factor (PDF), placental bone morphogenetic protein (PLAB), NSAID activated gene-1 (NAG-1), and PL74 [5, 6]. Initially GDF- 15 was reported to inhibit TNF- $\alpha$ production in lipopolysaccharide-stimulated macrophages and thus named as macrophage inhibitory cytokine-1(MIC-1) [7]. However, Subsequent studies did not confirm the same concept of macrophage suppression [8].

GDF-15 is produced as $a \approx 40 \mathrm{kDa}$ propeptide form. The $\mathrm{N}$ terminus is cleaved and released as $a \approx 30 \mathrm{kDa}$ disulphide linked dimeric active protein form [9]. GDF-15 is a growth factor whose expression increases with age. Biologic age is related to the several markers such as oxidative stress, protein glycation, inflammation, and hormonal changes. Many of these stresses induce GDF-15 expression by either p53 or early growth response protein -1 (EGR-1) transcription factors [1012]. GDF-15 levels are also affected by environmental factors independently of genetic background. One study found that GDF-15 level is a novel and powerful predictor of all-cause mortality in general population and independent of several markers associated with mortality risk including age, body mass index (BMI), smoking history, IL-6, CRP, and telomere length [13].

Higher level of GDF-15 is associated with increased cardiovascular and noncardiovascular mortality; it plays pivotal role in development and progression of cardiovascular diseases such as heart failure, coronary artery diseases, atrial fibrillation, diabetes, cancer, and cognitive impairment (Figure 1) [14, 15]. Increased GDF-15 expression is a feature of many cancers including breast, colon, pancreas, and prostate. Many epithelial tumor cell lines secrete high levels of GDF15. Several studies showed that higher expression of GDF$15 \mathrm{mRNA}$ and protein was found in cancer biopsies [16-18]. High expression of GDF-15 in tumor is also associated with an increase in serum GDF-15 levels, suggesting the use of serum GDF-15 measurement for the diagnosis and management of cancer $[9,18-20]$. In this present review, we described all studies on GDF-15 that reports its role in diabetes and cardiovascular diseases. We explained how GDF-15 could be used as a prognostic and diagnostic biomarker for cardiometabolic

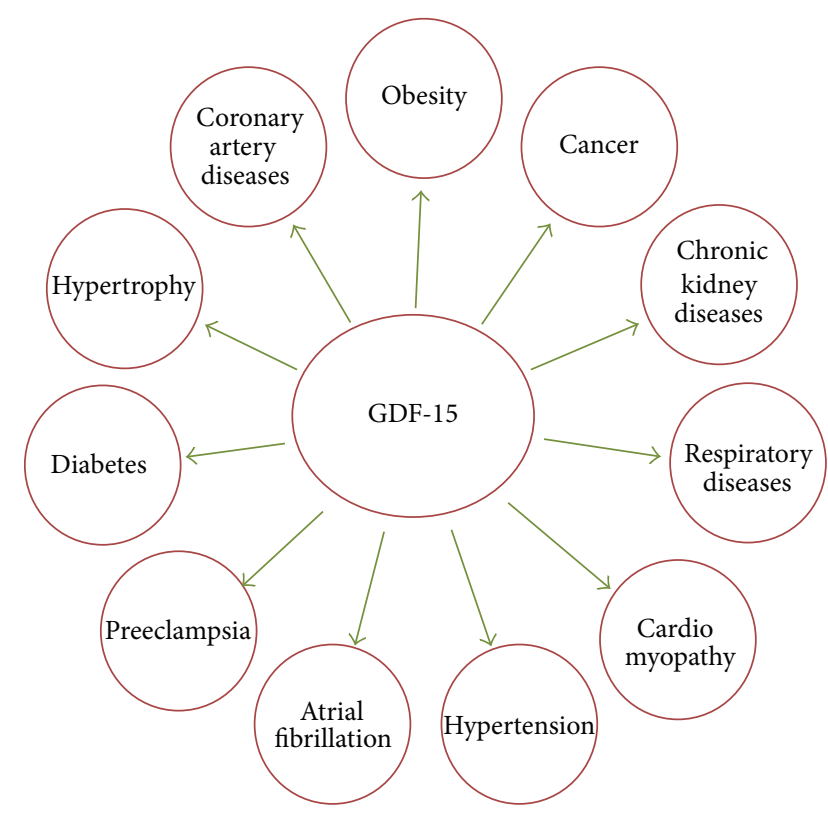

FIGURE 1: Role of GDF-15 in different diseases conditions. GDF15 plays an important role to modulate metabolic, cardiovascular, obesity, cancer, and chronic disease.

diseases. We have also looked into the potential of GDF-15 as a novel target for diabetes and cardiovascular diseases.

\section{GDF-15 Expression and Release}

GDF-15 is highly expressed in the placenta and prostate but also expressed in heart, pancreas, liver, kidney, and colon $[6,46,47]$. It is a stress-induced cytokine and also releases from macrophages [48], vascular smooth muscle cells [49], cardiomyocytes, adipocytes [50], and endothelial cells [51] after tissue injury, anoxia, and proinflammatory cytokines responses. GDF-15 plays a role as an endocrine factor if present in circulation [52]. GDF-15 highly expressed in response to different kinds of cytokines and growth factors like interleukin-1 $\beta$ (IL-1 $\beta$ ), TNF- $\alpha$, angiotensin II, macrophage colony stimulating factor (M-CSF), and TGF- $\beta$. Tumor suppressor protein p53 also induces GDF-15 and thus acts as a growth inhibitory molecule in tissue $[7,46,47,53]$. GDF-15 expression is highly induced in cardiomyocytes after ischemia/reperfusion [53]. Increased expression of GDF15 was observed in the mouse and human heart within hours after myocardial infarction and remains elevated in the infarcted myocardium for several days. Cardiomyocytes in the infarct border zone have been identified as the main source of GDF-15 [54]. There is a controversy regarding the production sites of GDF-15 during heart failure conditions. Although GDF-15 is strongly released from the infracted human heart [54], it may also be released from macrophages [48]. Lok et al. reported that there is no evidence for the myocardial expression of GDF-15 in patients having advanced nonischemic heart failure. However, the circulating GDF15 levels were increased the same as cardiac troponin and natriuretic peptides levels in serum. This study indicates that 
TABLE 1: List of human studies dealing with GDF-15 levels in obesity and diabetes.

\begin{tabular}{|c|c|c|c|}
\hline Disease/population/follow-up period & Sample size & Major findings & Reference \\
\hline $\begin{array}{l}\text { T1DM patients with diabetic nephropathy } \\
\text { (8.1 years) }\end{array}$ & 451 & $\begin{array}{l}\text { GDF-15 can be used to detect faster deterioration of } \\
\text { kidney function }\end{array}$ & {$[21]$} \\
\hline $\begin{array}{l}\text { Obese nondiabetic (XENDOS) trial } \\
\text { (4 years follow Up period) }\end{array}$ & 496 & $\begin{array}{l}\text { GDF-15 is altered among patients having abdominal } \\
\text { obesity and insulin resistance and independently } \\
\text { associated with future insulin resistance and abnormal } \\
\text { glucose control }\end{array}$ & {$[22]$} \\
\hline Morbidly obese patients & 118 & $\begin{array}{l}\text { GDF-15 changes following bariatric surgery suggest an } \\
\text { indirect relationship between GDF-15 and insulin } \\
\text { resistance }\end{array}$ & {$[23]$} \\
\hline $\begin{array}{l}\text { Type } 2 \text { diabetes (whitehall II study) } \\
(11.5 \pm 3.0 \text { years follow up period) }\end{array}$ & 552 & $\begin{array}{l}\text { Baseline GDF-15 concentrations were increased in } \\
\text { individuals before type } 2 \text { diabetes manifestation }\end{array}$ & {$[24]$} \\
\hline $\begin{array}{l}\text { Patients with obesity and/or obesity and } \\
\text { type } 2 \text { diabetes mellitus }\end{array}$ & 54 & $\begin{array}{l}\text { Elevated GDF-15 levels in patients with obesity are } \\
\text { further increased by the presence of T2DM }\end{array}$ & {$[25]$} \\
\hline Preeclampsia and diabetic pregnancies & 267 & $\begin{array}{l}\text { GDF-15 is dysregulated, both in preeclampsia and in } \\
\text { diabetic pregnancies }\end{array}$ & {$[26]$} \\
\hline $\begin{array}{l}\text { Patients with T2DM included in screened } \\
\text { for the presence of diabetic cardiomyopathy } \\
\text { (DC) }\end{array}$ & $\mathrm{T} 2 \mathrm{DM}(n=213)$ & $\begin{array}{l}\text { GDF-15 represents a useful and novel tool to screen } \\
\text { diabetic cardiomyopathy (DC) in patients with type } 2 \\
\text { DM }\end{array}$ & {$[27]$} \\
\hline Diabetic nephropathy & $\begin{array}{l}\text { T2DM }(n=30), \\
\text { microalbuminuria } \\
\quad(n=20), \\
\text { macroalbuminuria } \\
(n=30) \text { patients }\end{array}$ & $\begin{array}{l}\text { Suggesting its value in early diagnosis, evaluation, and } \\
\text { prediction of the outcomes of type } 2 \text { diabetic } \\
\text { nephropathy }\end{array}$ & {$[28]$} \\
\hline
\end{tabular}

GDF-15 may also be released outside of the heart $[55,56]$. Strelau et al. reported that GDF-15 is highly expressed in the central nervous system (CNS) and peripheral nervous system (PNS), mainly in the choroid plexus and is secreted into the cerebral spinal fluid (CSF) [57]. Wiklund et al. have stratified the blood GDF-15 levels into three categories, that is, normal $(<1200 \mathrm{pg} / \mathrm{mL})$, moderately elevated (1200-1800 pg/mL), and highly elevated (>1800 pg/mL). They reported that $61 \%$ people survived when GDF-15 levels were more than $1800 \mathrm{pg} / \mathrm{mL}^{-1}$ [13].

\section{GDF-15, Obesity, and Diabetes}

Obesity is a risk factor for diabetes and cardiovascular diseases. Excess body weight is associated with increased health problems and cause increased cardiovascular morbidity and mortality [58]. GDF-15 released from macrophages, liver and white adipose tissue may act as a metabolic regulator. GDF-15 acts as adipokine like adiponectin and leptin [50] and thus has also been termed as cardiokine [59]. Adipokines, in general, regulate the lipid and glucose metabolism, increase insulin sensitivity, regulate food intake and body weight, and protect from chronic inflammation in adipose tissue [3]. Recently Macia et al. found that GDF-15 decreases food intake, body weight, and adiposity and improves glucose tolerance in normal and obesogenic diets [60]. Several human studies dealing with GDF-15 levels in obesity and diabetes are shown in Table 1. Serum GDF-15 levels were increased in obese and type 2 diabetic women and correlated with body mass index (BMI), body fat, glucose, and C-reactive proteins [50]. Vila et al. reported that median interquartile range
(IQR) plasma GDF-15 was 427 (344-626) $\mathrm{ng} / \mathrm{mL}$ in obese patients as compared to the controls 309 (275-411) ng/mL. Increased GDF-15 levels are strongly associated with waist to height ratio, age, arterial blood pressure, triglycerides, creatinine, glucose, insulin, glycated hemoglobin (HbAlc), and C-peptide. Age, insulin resistance, and creatinine were independent predictors of GDF-15 in obese patients [23]. Recently Chrysovergis et al. reported that GDF-15 is a novel therapeutic target in preventing and treating obesity and insulin resistance by modulating metabolic activity through increased expression of key thermogenic and lipolytic genes in brown adipose tissue (BAT) and white adipose tissue (WAT) [61].

Hyperglycemia is one of the main chronic symptoms of diabetes. In hyperglycemic conditions, increased reactive oxygen species (ROS) formation leads to cellular injury and cell death $[61,62]$. Increased ROS generation in HUVEC cells can cause apoptosis by inhibiting the PI3 K/AKT/eNOS/NO pathway and activation of $\mathrm{NF}-\kappa \mathrm{B} / \mathrm{JNK} /$ caspase- 3 pathway [63]. Li et al. proved that increased GDF-15 protects endothelial cells against high glucose induced cellular injury by activating PI3 K/AKT/eNOS signaling pathway and attenuating NF- $\kappa \mathrm{B} / \mathrm{JNK}$ activation. Nitric oxide production was significantly lower in GDF-15 siRNA transfected HUVEC cells. This study concluded that GDF-15 plays protective role against cell apoptosis through PI3 K/Akt/eNOS pathway but not ERK1/2 and SMAD2/3 (Figure 2) [5]. They found that high glucose increases GDF-15 expression and its secretion, which modulates cell apoptosis in negative feedback manner [5]. As discussed before, GDF-15 is expressed by the adipose tissue through p53, a transcriptional factor that links GDF-15 


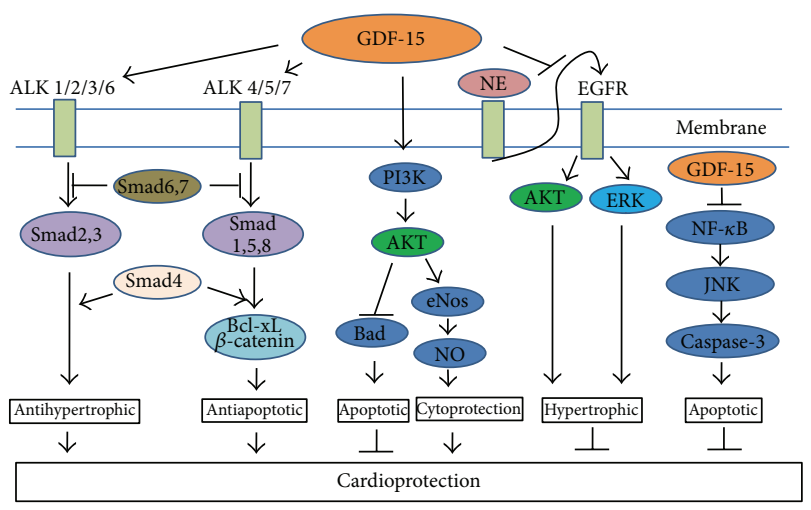

FIGURE 2: GDF-15 regulates signaling pathways essential for cardioprotection. GDF-15 shows cardioprotective effect through activation of ALK type 1 receptors (ALK 1-7) and phosphorylation of Smad2/3 and Smad1/5/8. After phosphorylation, Smad translocates to the nucleus in the form of heteromeric complex with Smad 4 and activates antihypertrophic pathway. GDF-15 also activates PI3 K/AKT/eNOS/NO pathway and shows cardioprotection. GDF15 inhibits epidermal growth factor receptor (EGFR) transactivation and $\mathrm{NF}-\kappa \mathrm{B} / \mathrm{JNK} /$ caspase-3 pathway to show its cardioprotective effect.

with obesity and insulin resistance. Expression of GDF15 is controlled by both p53 dependent and independent mechanisms $[46,64]$. Li et al. explained that increase in GDF-15 expression by high glucose in HUVEC cells was p53 dependent pathway. Inhibition of high glucose-induced p53 accumulation by p53 siRNA abolished GDF-15 induction [5]. Obesity promotes p53 activation in adipose tissue and leads to increased production of proinflammatory cytokines, insulin resistance, and diabetes. GDF-15 expression is rapidly induced by proinflammatory cytokines and thus serves as a marker for inflammation in adipose tissue [22, 25, 50, 65]. Insulin resistance and increased GDF-15 both are associated with endothelial dysfunction. The endothelial dysfunction may lead to metabolic derangement, inflammation. and vascular injuries and is associated with increased cardiovascular complications [22]. Increased glucose level in urine and decreased expression of glucose transporters (Glut 1, Glut 2, SGLT 1, and SGLT 2) was observed in type 2 diabetic GDF-15 knockout mice. Similar increased urinary volume was observed in streptozotocin (STZ) induced mice without any alteration of glucose transporters. GDF-15 expression was upregulated within the first 7 days of STZ induced diabetic rats and mice [66]. Khan et al. explained in their study that GDF-15 but not NT-proBNP is raised in patients who have diabetes. Diabetes independently influences the levels of GDF-15 [29]. XENDOS study reported that plasma GDF-15 levels are positively associated with HOMA-IR, an index of insulin resistance [22].

Activated macrophages will secrete proinflammatory, chemotactic cytokines, and chemokines that impair $\beta$ cells function, insulin sensitivity, and infiltration of monocytes into the tissues $[24,67]$. Several studies reported that numbers of macrophages were increased in pancreatic islets in type 2 diabetic patients [68]. GDF-15 concentration in plasma was increased in individuals with early stages of T2DM manifestation. Dostalova et al. reported that serum concentration of GDF-15 was increased approximately 1.2- and 2-fold in obese and T2DM women patients, respectively, compared to control subjects. Serum GDF-15 levels are positively correlated with body weight, body fat, triglyceride, glucose, HbAlc, and C-reactive protein [25]. Sugulle et al. observed that plasma GDF-15 levels was elevated in preeclampsia (5978 median (3822-15652 IQR) ng/L) and superimposed preeclampsia in diabetes mellitus (6002 (4230-11830) ng/L) compared to the control subjects (3710 (1860-6266) ng/L) [26]. However some group of scientists believed that it is not associated with the incident type 2 diabetes rather its increase in plasma might be part of anti-inflammatory response for the onset of diabetes [24]. Scientific data showed that serum GDF-15 could be a potential marker to identify individuals who are at risk for diabetes and obesity. However, a longitudinal study should be done where we can identify the early stage of a disease when GDF-15 level starts to increase in serum. More research needs to be carried out to find if administration of GDF-15 has any role to reduce inflammation or early pathological changes in diabetes and obesity.

\section{GDF-15 and Cardiovascular Diseases}

Cardiovascular (CV) diseases, that is, atherosclerosis, hypertension, hypertrophy or heart failure, myocardial infarction (MI), coronary artery disease (CAD), or stroke, are the most prevalent diseases and major cause of the death worldwide [69]. Aging, diabetes, and other risk factors will increase the disease progression by inducing left ventricular hypertrophy, endothelial dysfunction, hypertension, and vascular diseases [65]. GDF-15, the first TGF- $\beta$ protein family, plays a cardioprotective role in the adult heart through activation of Smad2, Smad3, and ALK4/5/7 receptors [70]. GDF-15 is not expressed in heart under normal physiological conditions but increases rapidly in response to cardiovascular injury, such as pressure overload, heart failure, ischemia/reperfusion, and atherosclerosis [54, 71]. Several human studies dealing with GDF-15 levels in cardiovascular diseases are shown in Table 2. GDF-15 showed antiapoptotic effect against ischemia reperfusion (I/R) and reduced the size of myocardial infarction (MI). GDF-15 activates Smad1 and reduces apoptotic cell death through upregulation of Bcl-xL and $\beta$-catenin. Similarly, BMP-2 also exerts antiapoptotic effect through activation of Smad1. GDF-15 and BMP-2 show similarities in their primary structure and Smad activation. GDF-15 is more close to the BMP- 2 family than the TGF- $\beta$ subfamily. BMP-2 activates ALK-2/3/6 and phosphorylates Smad1/5. Similarly, GDF-15 activates type I receptors and Smad1/5 [70]. All these signaling pathways regulated by GDF-15 are responsible for cardioprotection (Figure 2).

GDF-15 predicts adverse outcomes in patients with acute chest pain, MI, or chronic angina $[29,30,45,72]$. GDF-15 is an emerging biomarker, as it is elevated in early subclinical disease and has prognostic utility for cardiovascular events and mortality [37]. Recent findings showed that GDF-15 levels were associated with lower left ventricular ejection fraction 
TABLE 2: List of human studies dealing with GDF-15 levels in cardiovascular diseases.

\begin{tabular}{lcl}
\hline $\begin{array}{l}\text { Disease/population/follow-up period } \\
\text { Acute myocardial infarction [AMI] }\end{array}$ & Sample size & Major findings \\
$\begin{array}{lll}\text { Acute coronary syndrome [ACS] } \\
\text { (PROVE IT-TIMI 22) }\end{array}$ & $\begin{array}{l}\text { GDF-15 is a prognostic marker of death and HF in } \\
\text { patients with AMI Multimarker approach with GDF-15 } \\
\text { and NT-pro-BNP is more informative than either } \\
\text { marker alone and may be useful for risk stratification in } \\
\text { AMI patients }\end{array}$ \\
\hline $\begin{array}{l}\text { Human model of acute muscle wasting } \\
\text { following cardiac surgery }\end{array}$ & \multirow{2}{*}{4501} & $\begin{array}{l}\text { GDF-15 is altered with recurrent events after ACS. } \\
\text { GDF-15 may be used as a prognostic marker in ACS }\end{array}$ \\
\hline $\begin{array}{l}\text { Non-ST-elevation ACS (FRISC-II) trial } \\
\text { (2 years) }\end{array}$ & $\begin{array}{l}\text { GDF-15 is a potential novel factor associated with } \\
\text { muscle atrophy, which may become a therapeutic target } \\
\text { in patients with ICU acquired paresis and other forms } \\
\text { of acute muscle wasting }\end{array}$ \\
\hline
\end{tabular}

General adult population

(Dallas Heart Study)

GDF-15 is independently marker for subclinical coronary atherosclerosis and mortality

(7.3 years follow up period)

\section{Framingham Offspring}

cohort participants

( 9.5 years follow up period)

Hypertensive left ventricular hypertrophy

(H-LVH), hypertensive cardiomyopathy (HCM)

Patients with preclinical diastolic

dysfunction or heart failure with normal

ejection fraction (HFnEF)

Patients with stable ischemic heart disease

(Heart and Soul study)

(8.9 yrs follow-up period)

Untreated hypertensive patients

Higher circulating GDF-15 was observed with incident renal outcomes and improves risk prediction of incident chronic kidney diseases (CKD)

149

GDF-15 might be a useful biomarker for discriminating HCM from H-LVH

GDF-15 levels are elevated in subjects with HFnEF and

119 can differentiate normal diastolic function from asymptomatic LVDD

Higher GDF-15 level was observed with major

984 cardiovascular (CV) events in patients with stable

In elderly men, GDF-15 improves progression of both

71-year-old men

(ULSAM study)

Heart failure

(Val-HeFT study)

1734

299

Coronary artery diseases (CAD)

$\mathrm{CAD}(n=348)$ and

$(n=205)$ controls

Coronary Artery Bypass Grafting with

Cardiopulmonary Bypass

34 patients

\begin{tabular}{cc}
\hline Pemodialysis \\
$(n=87)$, and \\
Patients on maintenance hemodialysis
\end{tabular}$\quad \begin{gathered}\text { conts }(n=45) \\
\end{gathered}$

ST segment elevation myocardial infarction (STEMI) (3 years)
Patients with STEMI
$(n=216)$

Acute chest pain

(APACE study) ischemic heart disease

Plasma GDF-15 level was increased with LVH in hypertensive patients

cardiovascular, cancer mortality, and morbidity beyond established risk factors and biomarkers of cardiac, renal dysfunction, and inflammation

Providing independent prognostic information in heart failure

Significant differences of GDF-15, IMA, and PAPP-A in patients with CAD. GDF-15 might be associated with severity of CAD

GDF-15 levels were increased substantially and it is associated with the renal and cardiac biomarkers

Relation between GDF-15, mortality, and carotid artery thickening suggests that GDF-15 may be a novel marker of atherosclerosis, inflammation, and malnutrition in hemodialysis patients

High GDF-15 level is a strong predictor of death and heart failure in patients with STEMI. Although patients with higher GDF-15 levels tend to have lower LV ejection fraction

GDF-15 is a better predictor of mortality than of

646 nonfatal CV events

nonfatal CV events


(LVEF), worse diastolic function, greater inducible ischemia, and lower exercise capacity. GDF-15 is also correlated with NT-proBNP, reduced plaque burden, left ventricular mass, concentric left ventricular hypertrophy, coronary artery disease, and heart failure [37, 73]. Role of GDF-15 in different cardiovascular diseases condition is described below.

4.1. Hypertrophy. Cardiac hypertrophy is typically characterized by enlargement of the heart associated with an increase in cardiomyocyte cell size in response to physiological stimuli such as exercise and pathophysiological stimuli such as hypertension, ischemic heart diseases, valvular insufficiency, infectious agents, or mutations in sarcomeric genes [71]. Hypertensive patients are more prone to left ventricular hypertrophy $(\mathrm{LVH}) . \mathrm{LVH}$ is an early change for the cardiac damage in hypertension [74]. The prevalence of LVH in hypertensive patients was about $25 \%$ to $35 \%$ in China $[75,76]$. It has been shown that $\mathrm{LVH}$ increases the risk of stroke, coronary heart disease, congestive heart failure, arrhythmias, and sudden cardiac death. All these are associated with cardiovascular morbidity and mortality, as all-cause mortality [77, 78]. Serum GDF-15 levels in hypertensive patients were significantly higher than in healthy volunteers and positively correlated with the thickness of the posterior wall of the left ventricle, interventricular septum, and left ventricular mass, as well as the serum level of norepinephrine [79]. Plasma GDF-15 levels in hypertensive patients with LVH was higher than those hypertensive patients without LVH. They observed positive correlation between plasma GDF15 levels and LVH in hypertensive patients which indicates that GDF-15 may be involved in the development of LVH in hypertension [79]. Hantani et al. found that GDF-15 might be a useful biomarker for discriminating hypertrophic cardiomyopathy (HCM) from hypertensive left ventricular hypertrophy $(\mathrm{H}-\mathrm{LVH})$. It was also observed that serum GDF-15 levels were significantly higher in patients with $\mathrm{H}$ LVH than with HCM, and thus GDF-15 is an independent predictor of $\mathrm{H}-\mathrm{LVH}$. The data suggest that GDF-15 levels may help to introduce different treatment strategies for treating HCM and H-LVH [80]. One of the recent studies shows that GDF-15 is an autocrine/paracrine factor that attenuates the cardiac hypertrophy in experimental models via SMAD and kinases (PI3 K and ERK) signaling pathways. This study indicates that GDF-15 works through activation of SMAD protein and kinases, that is, PI3 K and ERK mechanism [71].

Intracellular mechanism of TGF- $\beta$ family is divided into Smad dependent and Smad independent pathway. This intracellular mechanism is determined by the type 1 receptors (ALK1 to 7 ). GDF-15 activates type 1 receptor and phosphorylates Smad2/3 and Smad1/5/8, which translocate to the nucleus in the form of heteromeric complex with Smad4 [70]. Smad4 is a common transcriptional mediator of the Smad dependent pathway. Wang et al. reported that heart specific deletion of $\operatorname{smad}^{-/-}$( $\mathrm{smad}^{-/-}$mice) showed greater cardiac hypertrophy and heart failure [55]. Xu et al. suggested that Smad dependent pathway can inhibit apoptosis and shows protection against hypertrophy and fibrosis [79]. Xu et al. proposed a protective mechanism of GDF-15 against cardiac hypertrophy and cell death through Smad protein activation. It was explained in the study that GDF-15 shows TGF- $\beta$ /activin-like response through Smad2/3. While Smad2 overexpression showed the similar beneficial effects of GDF15, overexpression of Smad6 or Smad7 reversed its antihypertrophic effects [78]. GDF-15 treatment transiently activates the Akt and ERK1/2 signaling [71]. Akt activation regulates cardiomyocyte viability [53] whereas ERK1/2 signaling regulates the cell survival [81]. Both pathways are cardioprotective in nature, thus, most of the data confirm that GDF-15 is a novel antihypertrophic as well as cardioprotective regulatory factor $[29,71]$.

GDF-15 was found to inhibit myocardial hypertrophy through a $S m a d 2 / 3$ pathway in a pressure-induced hypertrophy model [71]. Similarly Xu et al. reported that GDF15 protects the heart from norepinephrine (NE) induced hypertrophy through Smad independent pathway [71]. Different Smad independent pathways through which GDF15 works are MAPKs, TAK-1, and PI3 K/AKT pathways [82]. GDF-15 also inhibits norepinephrine-induced myocardial hypertrophy by inhibition of epidermal growth factor receptor (EGFR) transactivation and phosphorylation of downstream kinases, that is, Akt and extracellular signalregulated kinases (ERK) (Figure 2) [79]. In contrast, GDF-15 results in prohypertrophic effect in cardiomyocytes through a Smadl pathway [83].

Recently, one study observed that GDF-15 is a novel promising biomarker in heart failure with normal ejection fraction (HFnEF). It is elevated in subjects with either mild or moderate to severe left ventricular diastolic dysfunction (LVDD) regardless of the presence of CAD or other established risk factors frequently associated with HFnNF [84]. Lok et al. reported for the first time that highly elevated GDF15 levels can be reversible in some extent, after measuring GDF-15 before and after intervention with left ventricular assist device (LVAD) in New York Heart Association (NYHA) class IV, nonischaemic, and nonvalvular HF patients. They found that the GDF-15 levels were gradually reduced after implantation. This finding suggests that GDF-15 could be used as prognostic marker to measure the response to a potentially life-saving therapeutic intervention such as LVAD implantation [56]. Other studies like valsartan heart failure trial (Val-HeFT trial) indicated that higher GDF-15 levels are associated with many pathological processes and then linked to the severity and progression of heart failure (HF), including neurohormonal activation, inflammation, myocyte death, and renal dysfunctions. Higher GDF-15 levels are associated with adverse outcomes independent of established clinical and biochemical risk factors [40,65]. Recently, Chen et al. demonstrated that olmesartan prevents cardiac rupture in mice with myocardial infarction (MI) through inhibition of apoptosis and inflammation and is associated with downregulation of p53 activity and upregulation of myocardial GDF-15 [85]. In contrast, irbesartan (AT1 receptor blocker) significantly reduced angiotensin II induced GDF-15 expression in cardiomyocytes [86]. The above studies indicate that angiotensin receptor blockers regulate GDF-15 expression. However, more therapeutic intervention studies are needed to understand whether GDF-15 can be used as 
a prognostic marker for therapeutic intervention for different cardiovascular disorders.

4.2. Atherosclerosis. Development and progression of atherosclerotic plaques are driven by endothelial dysfunction, oxidized low-density lipoprotein (oxLDL) deposition in the subendothelial space, recruitment of inflammatory monocytes to the arterial vessel wall, their differentiation into activated macrophages, and subsequent transformation into cholesterol-laden foam cells in the subendothelial space [87]. It has been shown that GDF-15 inhibits proliferation of endothelial cells (ECs) in vitro and in vivo. A recent study demonstrated that GDF-15 at high concentration $(50 \mathrm{ng} / \mathrm{mL})$ inhibits EC proliferation, whereas, at lower concentrations ( $5 \mathrm{ng} / \mathrm{mL})$, GDF-15 caused endothelial cell proliferation and was found proangiogenic [50,88-90].

Transforming growth factor betas (TGF $\beta$ s) have been involved in many of the pathophysiological process mainly in the vascular diseases. It will act as inflammatory markers in advanced stage of atherosclerosis and play a role in pathogenesis of ischemic heart diseases. TGF $\beta$ s involved in the pathogenesis of atherosclerosis by activating proteolytic mechanism of activated macrophages [91-94]. These activated macrophages will undergo apoptosis in lipid rich plaque condition. This phenomenon pointing out that lipid content and inflammatory cell viability may be responsible for the thrombogenicity [95]. Activation of caspase 3, induction of manganese superoxide dismutase (MnSOD), and increase in expression of p53 were seen in human atherosclerotic plaques [96-100]. Signal transduction of oxLDL and its mediator's ceramide and TNF- $\alpha$ induce apoptosis in human activated macrophages [97, 98, 101-103]. Poly(ADP-ribose) polymerase (PARP), c-Jun-AP-1, and apoptosis inducing factor (AIF) were detected in apoptotic cells [49, 97101, 103]. Recently, Schlittenhardt et al. found that GDF15 is expressed in macrophages after stimulation by several biological mediators, including tumor necrosis factor $\alpha$ (TNF- $\alpha$ ), C6-ceramide, interleukin-1 (IL-1), macrophagecolony stimulating factor (M-CSF), oxLDL, and hydrogen peroxide. In human atherosclerotic carotid arteries, GDF15 (immunoreactivity) was exclusively localized in activated macrophages and colocalized with oxLDL, MnSOD, AIF, caspase-3 (CPP32), PARP, c-Jun/AP-1, and p53. GDF-15 is supposed to contribute to modulation of apoptosis and inflammatory processes of activated macrophages. All data suggested that increased expression of GDF-15 is associated with the development and progression of atherosclerotic plaques, possibly through the regulation of apoptotic processes [49]. In support of previous statement another study demonstrated that GDF-15 deficiency attenuates early atherogenesis and improves plaque stability by attenuating CCR2 (C-C chemokine receptor type 2) mediated macrophage chemotaxis. Similarly, deficiency of GDF-15 in leukocytes improves atherosclerotic plaque stability by impairing macrophage migration and inducing collagen deposition. A novel function of GDF-15 is to regulate the CCR2-dependent macrophage chemotaxis and proceeds via TGF- $\beta$ receptor II and its downstream effector GRK-2 [104].
Another function of GDF-15 is to control inflammatory process in cells. GDF-15 deficiency attenuates atherosclerosis by regulating interleukin-6 dependent inflammatory response to vascular injury. GDF-15 deficiency results in inhibition of atherosclerosis in mice despite an inhibition of apoptotic processes and an increase in cell density in atherosclerotic lesions. This implicates that inhibition of apoptosis acts as antiatherogenic. Regulation of apoptosis through GDF-15 may be a therapeutic strategy to control atherosclerosis and plaque progression [87]. Triglyceride-rich lipoproteins upregulate GDF-15 by $>5$-fold in human smooth muscle cells of coronary arteries [48]. This increased GDF-15 may trigger the prognosis of the diseases. Overall GDF-15 levels are increased in cardiovascular disease patients [105] and enhance the risk of atherosclerosis. However, GDF-15 deficiency in leukocytes protects against atherosclerosis [104].

4.3. Coronary Artery Diseases and Myocardial Infarction. Coronary artery disease (CAD) is a chronic degenerative condition. CAD is a combination of different clinical syndromes including stable angina, acute coronary syndrome (ACS), heart failure, arrhythmia, and death. Myocardial infarction, a condition associated with coronary artery disease, contributes to deaths [106]. Circulated levels of GDF-15 levels are increased in patients who are admitted to the hospital with an acute coronary syndrome. This was proved in "non-ST segment elevation ACS" patients in GUSTO 4 trial [106]. People with elevated levels of GDF-15 (>1800 ng/L) had a high risk for mortality within one year [105]. However, increased GDF15 level has beneficial role during invasive strategy. In the "Fast Revascularization during in Stability in Coronary artery disease II" (FRISC-II) trial with GDF-15 level <1200 ng/L did not show any benefit from the invasive strategy even though they had ST segment depression or a troponin T level $>0.01 \mu \mathrm{g} / \mathrm{L}$. Patients with GDF-15 levels $>1200 \mathrm{ng} / \mathrm{L}$, especially those with $1800 \mathrm{ng} / \mathrm{L}$ experienced significant reduction in the combined end point of death or myocardial infarction by the routine invasive strategy [32].

A recent Dallas Heart Study suggests that higher GDF15 is associated with prevalent coronary artery calcium (CAC) and cardiovascular mortality. People having GDF-15 concentrations $\geq 1800 \mathrm{ng} / \mathrm{L}$ were at increased risk for all-cause and cardiovascular death compared to those with $<1200 \mathrm{ng} / \mathrm{L}$. Increasing GDF-15 levels were associated with increasing age, diabetes, renal dysfunction, and inflammatory marker (CRP). Increasing GDF-15 was significantly correlated with black race, smoking, and hypertension. Increasing NT-proBNP concentrations are less associated with increasing GDF-15 levels, but there were no associations with BMI and sex differences [33].

Recently, elevated circulating GDF-15 levels that measured in individuals with acute myocardial infarction have been correlated with inflammatory biomarkers, suggesting a link between GDF-15 and inflammation [30, 32]. After cardiac surgery acute muscle wasting will occur because of imbalance between muscle atrophy and hypertrophy. Bloch et al. found that GDF-15 may be responsible for the skeletal muscle wasting in humans [31]. 
Recent study demonstrated that GDF-15 protects against fatal cardiac rupture in a mouse model of myocardial infarction. Induction of GDF-15 locally in the infarcted heart reduces the cardiac rupture by acting as an antiinflammatory cytokine and represses myeloid cell recruitment into the infarcted area [107]. GDF-15 also inhibits chemokine-triggered $\beta 2$ integrin activation on myeloid cells by activating Cdc42 and inhibition of small GTPase Rap1. Thus, GDF-15 is an inhibitor of leukocyte integrin that is one of the essential components to induce cellular injury after myocardial infarction [107].

In summary, GDF-15 is a very promising diagnostic marker for mild to moderate heart failure with normal ejection fraction or the absence of coronary artery diseases. However, more studies need to be done to distinguish different kinds of heart failure using GDF-15. Higher level of GDF-15 can predict the mortality for CAD patients. Some studies also showed its potential to use GDF-15 as a prognostic marker for therapeutic intervention for different cardiovascular disorders. Although the use of GDF-15 as a biomarker for cardiovascular disease is well established, its therapeutic application is debatable. While GDF-15 can show protection against cardiac hypertrophy, its increased expression is associated with the development and progression of atherosclerotic plaques. Further research is essential before considering GDF-15 as therapeutic intervention against cardiovascular diseases.

\section{GDF-15 and Kidney Disease: Linkage between Diabetes and Cardiovascular Diseases}

Diabetic nephropathy is a progressive kidney disease and a well-known complication of long standing diabetes [108]. Myocardial damage is directly associated with the development of proteinuria and focal glomerulosclerosis [109]. Increase in circulating troponins was observed commonly in patients with chronic kidney diseases (CKD) and are associated with the kidney disease progression and death. The association of circulating troponin and kidney damage is related to cardiac injury, rather than diminished clearance [110]. Higher plasma GDF-15 was associated with incident of CKD and indicates rapid decline in renal function [111]. Higher levels of GDF-15 were predictive of deterioration of kidney function [21]. Studies on renal injury in animal models suggest two possible reasons for increase in GDF15 levels during renal diseases; either GDF-15 is less cleared from the circulation by the kidneys or synthesis of GDF-15 is increased in renal diseases, or both $[112,113]$. In diabetic renal injury, increases in urinary GDF-15 were associated with proximal tubule injury [114]. Thus the hypothesis of less clearance of GDF-15 from kidney is not true. Renal GDF15 expression also appears to be upregulated in response to metabolic acidosis [113] and kidney injury [113]. van Huyen et al. found that higher levels of GDF-15 are a predictive marker of cardiovascular mortality in patients with diabetic nephropathy besides other well-known cardiovascular risk factors like NT-proBNP and glomerular filtration rate (GFR)
[113]. Plasma GDF-15 levels were also increased with the mogensen stage in type 2 diabetic nephropathy, and, thus, it is an independent risk factor for increased microalbuminuria (mAlb). It is significantly correlated with mAlb and eGFR, and thus GDF-15 would be useful in early diagnosis, evaluation, and prediction of the outcomes of type 2 diabetic nephropathy [28]. Although some studies have been performed to find the correlation of plasma and urine GDF15 levels with kidney disease, there is no study to look into its potential as prognostic marker for kidney disease after intervention.

\section{GDF-15 and Nitric Oxide: Cross Talk in Diabetes and Cardiovascular Diseases}

Increased levels of GDF-15 were associated with reduced endothelium-dependent vasodilation in resistance vessels [73]. GDF-15 shows protective effect against high glucose induced endothelial cell injury by activation of PI3 K/AKT/ eNOS signaling pathway. GDF-15 is important to release NO level in endothelial cells. In a recent study, nitric oxide production was significantly lower in GDF-15 siRNA transfected HUVEC cells. On the other hand NO is also responsible to increase GDF-15 gene expression [5]. Nitric oxide is responsible to alter the gene expression through cGMP dependent and cGMP independent signaling pathway. In cGMP independent pathway, nitric oxide reacts with superoxide to form peroxynitrate. Kempf et al. observed that nitric oxide increased GDF-15 expression in cardiomyocytes through superoxide/peroxynitrate dependent pathway, a cGMP independent pathway [54]. Endothelial dysfunction or injury due to diabetes and smoking may induce inflammation and generate oxidative stress within the vessel wall [115]. Several authors mentioned that oxidative stress and proinflammatory cytokines can induce GDF-15 expression in macrophages and different other cells. Thus increased GDF15 is linked to oxidative stress, inflammation, and endothelial dysfunction [34, 49, 73, 116-118]. Further research is still needed to understand whether GDF-15 can modulate NO levels or vice-versa in other nonendothelial cells.

\section{GDF-15 a Potential Biomarker}

In the last two decades, we have enormous improvement in the biomarker discovery but only few biomarkers gained wide spread use in clinical practice such as troponin $\mathrm{T}$, troponin I, Nt-proBNP, and B-type natriuretic peptide (BNP) [14]. Recently, Kahli reported that GDF-15 levels increased gradually during and after coronary bypass grafting. This study concluded that GDF-15 levels might be used as a marker of cardiac injury and renal dysfunction [42]. Zhang et al. performed a study to find out multimarkers as predictors of cardiovascular events in patients with mild to moderate coronary artery lesions. This study examined nine plasma inflammatory cytokines, that is, cathepsin S, chemokine (C$\mathrm{X}-\mathrm{C}$ motif) ligand 16 (CXCL16), sopluble CD40 ligand, IL-10, placental growth factor, GDF-15, MMP-9, monocyte chemo attractant protein-1, and hs-CRP in 964 patients having 
TABLE 3: GDF-15 patents related to diabetes, cardiovascular diseases, and chronic kidney diseases.

\begin{tabular}{|c|c|c|}
\hline Patent & Applicant & Title \\
\hline WO2011144571A2 & F. Hoffmann-La Roche Ag & $\begin{array}{l}\text { GDF- } 15 \text { based means and methods for survival and recovery prediction in } \\
\text { acute inflammation }\end{array}$ \\
\hline WO2012138919A2 & Amgen Inc. & Method of treating or ameliorating metabolic disorders using GDF-15 \\
\hline WO2012146645A1 & F. Hoffmann-La Roche Ag & Diagnosis of kidney injury after surgery \\
\hline EP2336784A1 & Roche Diagnostics GmbH & $\begin{array}{l}\text { GDF-15 and/or Troponin T for predicting kidney failure in heart surgery } \\
\text { patients }\end{array}$ \\
\hline EP2388594A1 & Roche Diagnostics GmbH & $\begin{array}{l}\text { GDF-15 based means and methods for survival and recovery prediction in } \\
\text { acute inflammation }\end{array}$ \\
\hline WO2009141357A1 & $\begin{array}{l}\text { Roche Diagnostics Gmbh, } \\
\text { F. Hoffmann-La Roche Ag }\end{array}$ & GDF-15 as biomarker in type 1 diabetes \\
\hline US $8,771,961 \mathrm{~B} 2$ & $\begin{array}{l}\text { Roche Diagnostics } \\
\text { Operations, Inc. }\end{array}$ & Monitoring myocardial infarction and its treatment \\
\hline EP1884777A1 & $\begin{array}{l}\text { Medizinische Hochschule } \\
\text { Hannover }\end{array}$ & $\begin{array}{l}\text { Means and methods for assessing the risk of cardiac interventions based on } \\
\text { GDF-15 }\end{array}$ \\
\hline EP2439535A1 & F. Hoffmann-La Roche AG & $\begin{array}{l}\text { Diagnosis of diabetes related heart disease, GDF-15 and Troponin as } \\
\text { predictors for the development of type } 2 \text { diabetes mellitus }\end{array}$ \\
\hline WO2013113008A1 & Amgen Inc. & GDF-15 polypeptides-ameliorating metabolic disorders \\
\hline WO2010048670A1 & $\begin{array}{l}\text { St. Vincent's Hospital } \\
\text { Sydney Limited }\end{array}$ & Method of prognosis in chronic kidney disease \\
\hline WO2011073382A1 & Roche Diagnostics Gmbh & $\begin{array}{l}\text { GDF-15 and/or troponin T for predicting kidney failure in heart surgery } \\
\text { patients }\end{array}$ \\
\hline
\end{tabular}

mild to moderate lesions, and assessed their association with risk of cardiovascular events during 3 years of their follow-up study. It was concluded that cathepsin S, sopluble CD40 ligand, placental growth factor, and GDF-15 were instructive biomarkers for predicting cardiovascular diseases. This study showed that multimarkers approach is useful to significantly predict cardiovascular diseases progression than the individual marker approach [119].

Similarly, Schnabel et al. investigated 12 biomarkers including GDF-15, related to inflammation, lipid metabolism, renal function, and cardiovascular function and remodeling. These markers are C-reactive protein, GDF-15, neopterin, apolipoproteins AI, B100, cystatin C, serum creatinine, copeptin, C-terminal-proendothelin-1, midregional-proadrenomedullin (MR-proADM), midregional-proatrial natriuretic peptide (MR-proANP), and N-terminal-pro-B-type natriuretic peptide (Nt-proBNP). Blood was collected from 1781 stable angina patients in relation to nonfatal myocardial infarction and cardiovascular death $(n=137)$. The study concluded that Nt-proBNP, GDF-15, MR-proANP, cystatin $\mathrm{C}$, and MR-proADM are the strongest predictors of cardiovascular outcome among patients with stable angina [120].

Similar to other biomarkers, GDF-15 can also be used for diagnosis of diseases and help to select the therapy. GDF-15 diagnosis method is patented for diagnosing any subject suffering from an acute inflammation. GDF-15 is also patented for the diagnosis of kidney injury after surgery, prediction of kidney failure after heart surgery, and detection the prognosis of chronic kidney diseases. GDF-15 is patented as a biomarker for the type 1 diabetes and diabetes related heart diseases. Besides using GDF-15 as a biomarker, GDF-15 polypeptide itself is patented to treat or ameliorate metabolic disorders. Table 3 described briefly the list of patents with GDF-15 that used as biomarker for diabetes, cardiovascular disease, and kidney disease.

\section{Conclusion}

Previous studies revealed that GDF-15 could be a prognostic and diagnostic marker for the cardiovascular and diabetic diseases. Proper reference ranges of GDF-15 need to be established to identify the disease severity and risk stratification of the diseases. However, before accepting as a clinically useful biomarker, the following questions need to be answered. (1) Whether GDF-15 measurement can support therapeutic management? (2) Can it be used for the routine clinical practice or clinical measurement? (3) Whether GDF-15 level can give any diagnostic and prognostic information? (4) Whether it can be used to take clinical decision for any particular diseases like B-type natriuretic peptide (BNP) for the heart failure and troponin for the acute coronary syndrome (ACS). (5) GDF-15 can be used as a single marker or multi marker approach along with other individual marker. There is very little information regarding pathophysiological role of GDF-15 in diabetes, CAD, hypertension, and diabetes associated with cardiovascular diseases. More intervention studies like AT1 receptor antagonist need to be carried out to bring GDF-15 as a prognostic marker for diabetic and cardiovascular diseases. Further understanding regarding the signaling pathways of GDF-15 may help to discover novel therapies against diabetes and cardiovascular complications. 
Abbreviations

\begin{tabular}{|c|c|}
\hline ACS: & Acute coronary syndrome \\
\hline AKT: & Serine/threonine kinase (protein kinase B) \\
\hline AIF: & Apoptosis inducing factor \\
\hline AP-1: & Activator protein-1 \\
\hline APACE: & Acute coronary syndrome evaluation \\
\hline Bcl-xL: & B-cell lymphoma-extra large \\
\hline BMI: & Body mass index \\
\hline BMP-2: & Bone morphogenetic protein-2 \\
\hline BNP: & B-type natriuretic peptide \\
\hline CAC: & Coronary artery calcium \\
\hline CAD: & Coronary artery diseases \\
\hline Cdc42: & Cell division control protein 42 \\
\hline CKD: & Chronic kidney diseases \\
\hline CCR2: & C-C chemokine receptor type 2 \\
\hline cGMP: & Cyclic guanosine monophosphate \\
\hline CXCL16: & Chemokine (C-X-C motif) ligand 16 \\
\hline EGR-1: & Early growth response protein-1 \\
\hline ERK: & Extracellular signal-regulated kinases \\
\hline eNOS: & Endothelial nitric oxide synthase \\
\hline GRK-2: & G protein-coupled receptor kinase 2 \\
\hline HbAlc: & Glycated hemoglobin \\
\hline H-LVH: & Hypertensive left ventricular hypertrophy \\
\hline hs-CRP: & High-sensitivity C-reactive protein \\
\hline HUVEC: & Human vascular endothelial cells \\
\hline ICU: & Intensive care unit \\
\hline IDF: & International diabetic federation \\
\hline IL-10: & Interleukin-10 \\
\hline IMA: & Ischemia modified albumin \\
\hline JNK: & Jun-N-terminal kinase \\
\hline LVAD: & Left ventricular assist device \\
\hline LVH: & Left ventricular hypertrophy \\
\hline mAlb: & Microalbuminuria \\
\hline MMP-9: & Matrix metalloproteinase 9 \\
\hline MR-proADM: & Midregional-proadrenomedullin \\
\hline MR-proANP: & Midregional-proatrial natriuretic peptide \\
\hline $\mathrm{NF}-\kappa \mathrm{B}:$ & Nuclear factor kappa B \\
\hline Nt-proBNP: & N-terminal-pro-B-type natriuretic peptide \\
\hline oxLDL: & Oxidized low-density lipoprotein \\
\hline PI3 K: & Phosphoinositide 3-kinase \\
\hline PARP: & Poly (ADP-ribose) polymerase \\
\hline PAI-1: & Plasminogen activator inhibitor-1 \\
\hline PAPP-A: & Pregnancy associated plasma protein-A \\
\hline T1DM: & Type 1 diabetes mellitus \\
\hline T2DM: & Type 2 diabetes mellitus. \\
\hline
\end{tabular}

\section{Conflict of Interests}

The authors declare that there is no conflict of interests regarding the publication of this paper.

\section{References}

[1] International Diabetes Federation Diabetes Atlas, 6th edition, 2013.

[2] S. M. Grundy, B. Howard, S. Smith Jr., R. Eckel, R. Redberg, and R. O. Bonow, "Diabetes and cardiovascular disease-executive summary: conference proceeding for healthcare professionals from a special writing group of the American Heart Association," Circulation, vol. 105, no. 18, pp. 2231-2239, 2002.

[3] J. Kaur, "A comprehensive review on metabolic syndrome," Cardiology Research and Practice, vol. 2014, Article ID 943162, 21 pages, 2014.

[4] W. I. Sivitz, "Lipotoxicity and glucotoxicity in type 2 diabetes. Effects on development and progression," Postgraduate Medicine, vol. 109, no. 4, pp. 55-64, 2001.

[5] J. Li, L. Yang, W. Qin, G. Zhang, J. Yuan, and F. Wang, "Adaptive induction of growth differentiation factor 15 attenuates endothelial cell apoptosis in response to high glucose stimulus," PLoS ONE, vol. 8, no. 6, Article ID e65549, 2013.

[6] M. Yokoyama-Kobayashi, M. Saeki, S. Sekine, and S. Kato, "Human cDNA encoding a novel TGF- $\beta$ superfamily protein highly expressed in placenta," Journal of Biochemistry, vol. 122, no. 3, pp. 622-626, 1997.

[7] T. Kempf, M. Eden, J. Strelau et al., "The transforming growth factor- $\beta$ superfamily member growth-differentiation factor-15 protects the heart from ischemia/reperfusion injury," Circulation Research, vol. 98, no. 3, pp. 351-360, 2006.

[8] W. D. Fairlie, A. G. Moore, A. R. Bauskin, P. K. Russell, H. R. Zhang, and S. N. Breit, "MIC-1 is a novel TGF- $\beta$ superfamily cytokine associated with macrophage activation," Journal of Leukocyte Biology, vol. 65, no. 1, pp. 2-5, 1999.

[9] M. R. Bootcov, A. R. Bauskin, S. M. Valenzuela et al., "MIC-1, a novel macrophage inhibitory cytokine, is a divergent member of the TGF-beta superfamily," Proceedings of the National Academy of Sciences of the United States of America, vol. 94, no. 21, pp. 11514-11519, 1997.

[10] D. A. Brown, C. Stephan, R. L. Ward et al., "Measurement of serum levels of macrophage inhibitory cytokine 1 combined with prostate-specific antigen improves prostate cancer diagnosis," Clinical Cancer Research, vol. 12, no. 1, pp. 89-96, 2006.

[11] A. Simm, N. Nass, B. Bartling, B. Hofmann, R.-E. Silber, and A. Navarrete Santos, "Potential biomarkers of ageing," Biological Chemistry, vol. 389, no. 3, pp. 257-265, 2008.

[12] A. R. Bauskin, D. A. Brown, T. Kuffner et al., "Role of macrophage inhibitory cytokine-1 in tumorigenesis and diagnosis of cancer," Cancer Research, vol. 66, no. 10, pp. 4983-4986, 2006.

[13] F. E. Wiklund, A. M. Bennet, P. K. E. Magnusson et al., "Macrophage inhibitory cytokine-1 (MIC-1/GDF15): a new marker of all-cause mortality," Aging Cell, vol. 9, no. 6, pp. 1057-1064, 2010.

[14] B. Lindahl, "The story of growth differentiation factor 15: another piece of the puzzle," Clinical Chemistry, vol. 59, no. 11, pp. 1550-1552, 2013.

[15] L. Wallentin, Z. Hijazi, U. Andersson et al., "Growth differentiation factor-15, a marker of oxidative stress and inflammation, for risk assessment in patients with atrial fibrillation: insights from the apixaban for reduction in stroke and other thromboembolic events in atrial fibrillation (ARISTOTLE) trial," Circulation, vol. 130, no. 21, pp. 1847-1858, 2014.

[16] J. B. Welsh, L. M. Sapinoso, A. I. Su et al., "Analysis of gene expression identifies candidate markers and pharmacological targets in prostate cancer," Cancer Research, vol. 61, no. 16, pp. 5974-5978, 2001.

[17] P. Buckhaults, C. Rago, B. St. Croix et al., "Secreted and cell surface genes expressed in benign and malignant colorectal tumors," Cancer Research, vol. 61, no. 19, pp. 6996-7001, 2001.

[18] J. B. Welsh, L. M. Sapinoso, S. G. Kern et al., "Large-scale delineation of secreted protein biomarkers overexpressed in 
cancer tissue and serum," Proceedings of the National Academy of Sciences of the United States of America, vol. 100, no. 6, pp. 3410-3415, 2003.

[19] T. Liu, A. R. Bauskin, J. Zaunders et al., "Macrophage inhibitory cytokine 1 reduces cell adhesion and induces apoptosis in prostate cancer cells," Cancer Research, vol. 63, no. 16, pp. 50345040, 2003.

[20] D. A. Brown, R. L. Ward, P. Buckhaults et al., "MIC-1 serum level and genotype: associations with progress and prognosis of colorectal carcinoma," Clinical Cancer Research, vol. 9, no. 7, pp. 2642-2650, 2003.

[21] M. Lajer, A. Jorsal, L. Tarnow, H.-H. Parving, and P. Rossing, "Plasma growth differentiation factor-15 independently predicts all-cause and cardiovascular mortality as well as deterioration of kidney function in type 1 diabetic patients with nephropathy," Diabetes Care, vol. 33, no. 7, pp. 1567-1572, 2010.

[22] T. Kempf, A. Guba-Quint, J. Torgerson et al., "Growth differentiation factor 15 predicts future insulin resistance and impaired glucose control in obese nondiabetic individuals: results from the XENDOS trial," European Journal of Endocrinology, vol. 167, no. 5, pp. 671-678, 2012.

[23] G. Vila, M. Riedl, C. Anderwald et al., "The relationship between insulin resistance and the cardiovascular biomarker growth differentiation factor-15 in obese patients," Clinical Chemistry, vol. 57, no. 2, pp. 309-316, 2011.

[24] M. Carstensen, C. Herder, E. J. Brunner et al., "Macrophage inhibitory cytokine- 1 is increased in individuals before type 2 diabetes diagnosis but is not an independent predictor of type 2 diabetes: the Whitehall II study," European Journal of Endocrinology, vol. 162, no. 5, pp. 913-917, 2010.

[25] I. Dostalova, T. Roubicek, M. Bartlova et al., "Increased serum concentrations of macrophage inhibitory cytokine-1 in patients with obesity and type 2 diabetes mellitus: the influence of very low calorie diet," European Journal of Endocrinology, vol. 161, pp. 397-404, 2009.

[26] M. Sugulle, R. Dechend, F. Herse et al., "Circulating and placental growth-differentiation factor 15 in preeclampsia and in pregnancy complicated by diabetes mellitus," Hypertension, vol. 54, no. 1, pp. 106-112, 2009.

[27] A. Dominguez-Rodriguez, P. Abreu-Gonzalez, and P. Avanzas, "Usefulness of growth differentiation factor-15 levels to predict diabetic cardiomyopathy in asymptomatic patients with type 2 diabetes mellitus," The American Journal of Cardiology, vol. 114, no. 6, pp. 890-894, 2014.

[28] H. Li, F. Gao, Y. Xue, and Y. Qian, "Value of plasma growth differentiation factor-15 in diagnosis and evaluation of type 2 diabetic nephropathy," Nan Fang Yi Ke Da Xue Xue Bao, vol. 34, no. 3, pp. 387-390, 2014.

[29] S. Q. Khan, K. Ng, O. Dhillon et al., "Growth differentiation factor-15 as a prognostic marker in patients with acute myocardial infarction," European Heart Journal, vol. 30, no. 9, pp. 10571065, 2009.

[30] M. P. Bonaca, D. A. Morrow, E. Braunwald et al., "Growth differentiation factor-15 and risk of recurrent events in patients stabilized after acute coronary syndrome: observations from PROVE IT-TIMI 22," Arteriosclerosis, Thrombosis, and Vascular Biology, vol. 31, no. 1, pp. 203-210, 2011.

[31] S. A. A. Bloch, J. Y. Lee, S. J. Wort, M. I. Polkey, P. R. Kemp, and M. J. D. Griffiths, "S73 circulating regulators of acute muscle wasting in the critically ill: GDF-15 a potential novel driver of acute muscle wasting," Thorax, vol. 67, supplement 2, article A37, 2012.
[32] K. C. Wollert, T. Kempf, B. Lagerqvist et al., "Growth differentiation factor 15 for risk stratification and selection of an invasive treatment strategy in non-ST-elevation acute coronary syndrome," Circulation, vol. 116, no. 14, pp. 1540-1548, 2007.

[33] A. Rohatgi, P. Patel, S. R. Das et al., "Association of Growth differentiation factor- 15 with coronary atherosclerosis and mortality in a young, multi ethnic population: observations from the Dallas Heart Study," Clinical Chemistry, vol. 58, no. 1, pp. 172182, 2012.

[34] J. E. Ho, S.-J. Hwang, K. C. Wollert et al., "Biomarkers of cardiovascular stress and incident chronic kidney disease," Clinical Chemistry, vol. 59, no. 11, pp. 1613-1620, 2013.

[35] S. Hanatani, Y. Izumiya, S. Takashio et al., "Growth differentiation factor 15 can distinguish between hypertrophic cardiomyopathy and hypertensive hearts," Heart and Vessels, vol. 29, no. 2, pp. 231-237, 2014.

[36] W. Dinh, R. Füth, M. Lankisch et al., "Growth-differentiation factor-15: a novel biomarker in patients with diastolic dysfunction?" Arquivos Brasileiros de Cardiologia, vol. 97, no. 1, pp. 6575, 2011.

[37] D. W. Schopfer, I. A. Ku, M. Regan, and M. A. Whooley, "Growth differentiation factor 15 and cardiovascular events in patients with stable ischemic heart disease (The Heart and Soul Study)," American Heart Journal, vol. 167, no. 2, pp. 186-192, 2014.

[38] H. Xue, Z. Fu, Y. Chen et al., "The Association of Growth differentiation factor-15 with left ventricular hypertrophy in hypertensive patients," PLoS ONE, vol. 7, no. 10, Article ID e46534, 2012.

[39] L. Wallentin, B. Zethelius, L. Berglund et al., "GDF-15 for prognostication of cardiovascular and cancer morbidity and mortality in men," PLoS ONE, vol. 8, no. 12, Article ID e78797, 2013.

[40] I. S. Anand, T. Kempf, T. S. Rector et al., "Serial measurement of growth-differentiation factor-15 in heart failure: Relation to disease severity and prognosis in the valsartan heart failure trial," Circulation, vol. 122, no. 14, pp. 1387-1395, 2010.

[41] L. Y. Fan, Z. G. Jin, M. Zong et al., "Growth differentiation factor 15 , ischemia modified albumin and pregnancy-associated plasma protein A in patients with coronary artery disease," Clinical Laboratory, vol. 60, no. 6, pp. 973-982, 2014.

[42] A. Kahli, C. Guenancia, M. Zeller et al., "Growth differentiation factor-15 (GDF-15) levels are associated with cardiac and renal injury in patients undergoing coronary artery bypass grafting with cardiopulmonary bypass," PLoS ONE, vol. 9, no. 8, Article ID e105759, 2014.

[43] H. Yilmaz, H. T. Çelik, O. M. Gurel et al., "Increased serum levels of GDF-15 associated with mortality and subclinical atherosclerosis in patients on maintenance hemodialysis," Herz, 2014.

[44] J.-F. Lin, S. Wu, S.-Y. Hsu et al., "Growth-differentiation factor15 and major cardiac events," American Journal of the Medical Sciences, vol. 347, no. 4, pp. 305-311, 2014.

[45] N. Schaub, T. Reichlin, R. Twerenbold et al., "Growth differentiation factor-15 in the early diagnosis and risk stratification of patients with acute chest pain," Clinical Chemistry, vol. 58, no. 2, pp. 441-449, 2012.

[46] J. Koopmann, P. Buckhaults, D. A. Brown et al., "Serum macrophage inhibitory cytokine 1 as a marker of pancreatic and other periampullary cancers," Clinical Cancer Research, vol. 10, no. 7, pp. 2386-2392, 2004.

[47] M. Tan, Y. Wang, K. Guan, and Y. Sun, "PTGF-beta, a type beta transforming growth factor (TGF-beta) superfamily member, 
is a p53 target gene that inhibits tumor cell growth via TGFbeta signaling pathway," Proceedings of the National Academy of Sciences of the United States of America, vol. 97, no. 1, pp. 109-114, 2000.

[48] B. Bermúdez, S. López, Y. M. Pacheco et al., "Influence of postprandial triglyceride-rich lipoproteins on lipid mediated gene expression in smooth muscle cells of the human coronary artery," Cardiovascular Research, vol. 79, no. 2, pp. 294-303, 2008.

[49] D. Schlittenhardt, A. Schober, J. Strelau et al., "Involvement of growth differentiation factor-15/macrophage inhibitory cytokine-1 (GDF-15/MIC-1) in oxLDL-induced apoptosis of human macrophages in vitro and in arteriosclerotic lesions," Cell and Tissue Research, vol. 318, no. 2, pp. 325-333, 2004.

[50] Q. Ding, T. Mracek, P. Gonzalez-Muniesa et al., "Identification of macrophage inhibitory cytokine- 1 in adipose tissue and its secretion as an adipokine by human adipocytes," Endocrinology, vol. 150, no. 4, pp. 1688-1696, 2009.

[51] N. Ferrari, U. Pfeffer, R. Dell'Eva, C. Ambrosini, D. M. Noonan, and A. Albini, "The transforming growth factor- $\beta$ family members bone morphogenetic protein- 2 and macrophage inhibitory cytokine- 1 as mediators of the antiangiogenic activity of N-(4hydroxyphenyl) retinamide," Clinical Cancer Research, vol. 11, no. 12, pp. 4610-4619, 2005.

[52] A. R. Bauskin, D. A. Brown, S. Junankar et al., "The propeptide mediates formation of stromal stores of PROMIC-1: role in determining prostate cancer outcome," Cancer Research, vol. 65, no. 6, pp. 2330-2336, 2005.

[53] J. Jurczyluk, D. Brown, and K. K. Stanley, "Polarised secretion of cytokines in primary human microvascular endothelial cells is not dependent on N-linked glycosylation," Cell Biology International, vol. 27, no. 12, pp. 997-1003, 2003.

[54] T. Kempf, M. Eden, J. Strelau et al., "The transforming growth factor-beta superfamily member growth-differentiation factor15 protects the heart from ischemia/reperfusion injury," Circulation Research, vol. 98, no. 3, pp. 351-360, 2006.

[55] J. Wang, N. Xu, X. Feng et al., "Targeted disruption of Smad4 in cardiomyocytes results in cardiac hypertrophy and heart failure," Circulation Research, vol. 97, no. 8, pp. 821-828, 2005.

[56] S. I. Lok, B. Winkens, R. Goldschmeding et al., "Circulating growth differentiation factor-15 correlates with myocardial fibrosis in patients with non-ischaemic dilated cardiomyopathy decreases rapidly after left ventricular assist device support," European Journal of Heart Failure, vol. 14, no. 11, pp. 1249-1256, 2012.

[57] J. Strelau, A. Sullivan, M. Bottner et al., "Growth/differentiation factor-15/macrophage inhibitory cytokine-1 is a novel trophic factor for midbrain dopaminergic neurons in vivo," The Journal of Neuroscience, vol. 20, no. 23, pp. 8597-8603, 2000.

[58] K. M. Flegal, B. I. Graubard, D. F. Williamson, and M. H. Gail, "Cause-specific excess deaths associated with underweight, overweight, and obesity," Journal of the American Medical Association, vol. 298, no. 17, pp. 2028-2037, 2007.

[59] M. Shimano, N. Ouchi, and K. Walsh, "Cardiokines: recent progress in elucidating the cardiac secretome," Circulation, vol. 126, no. 21, pp. e327-e332, 2012.

[60] L. Macia, V. W.-W. Tsai, A. D. Nguyen et al., "Macrophage inhibitory cytokine 1 (MIC-1/GDF15) decreases food intake, body weight and improves glucose tolerance in mice on normal \& obesogenic diets," PLoS ONE, vol. 7, no. 4, Article ID e34868, 2012.
[61] K. Chrysovergis, X. Wang, J. Kosak et al., "NAG-1/GDF-15 prevents obesity by increasing thermogenesis, lipolysis and oxidative metabolism," International Journal of Obesity, 2014.

[62] I. Afanas'ev, "Signaling of reactive oxygen and nitrogen species in diabetes mellitus," Oxidative Medicine and Cellular Longevity, vol. 3, no. 6, pp. 361-373, 2010.

[63] F. M. Ho, W. W. Lin, B. C. Chen et al., "High glucose-induced apoptosis in human vascular endothelial cells is mediated through NF-kappaB and c-Jun NH2-terminal kinase pathway and prevented by PI3K/Akt/eNOS pathway," Cellular Signalling, vol. 18, no. 3, pp. 391-399, 2006.

[64] J. A. Kelly, M. Scott Lucia, and J. R. Lambert, "p53 controls prostate-derived factor/macrophage inhibitory cytokine/NSAID-activated gene expression in response to cell density, DNA damage and hypoxia through diverse mechanisms," Cancer Letters, vol. 277, no. 1, pp. 38-47, 2009.

[65] K. C. Wollert and T. Kempf, "Growth differentiation factor 15 in heart failure: an update," Current Heart Failure Reports, vol. 9, no. 4, pp. 337-345, 2012.

[66] M. Mazagova, H. Buikema, A. van Buiten et al., "Genetic deletion of growth differentiation factor 15 augments renal damage in both type 1 and type 2 models of diabetes," The American Journal of Physiology-Renal Physiology, vol. 305, no. 9, pp. F1249-F1264, 2013.

[67] H. Kolb and T. Mandrup-Poulsen, "An immune origin of type 2 diabetes?” Diabetologia, vol. 48, no. 6, pp. 1038-1050, 2005.

[68] J. A. Ehses, A. Perren, E. Eppler et al., "Increased number of islet-associated macrophages in type 2 diabetes," Diabetes, vol. 56, no. 9, pp. 2356-2370, 2007.

[69] World Health Organization, World Health Statistics 2012, World Health Organization, Geneva, Switzerland, 2012.

[70] T. Ago and J. Sadoshima, "GDF15, a cardioprotective TGF-beta superfamily protein," Circulation Research, vol. 98, no. 3, pp. 294-297, 2006.

[71] J. Xu, T. R. Kimball, J. N. Lorenz et al., "GDF15/MIC-1 functions as a protective and anti hypertrophic factor released from the myocardium in association with SMAD protein activation," Circulation Research, vol. 98, no. 3, pp. 342-350, 2006.

[72] K. M. Eggers, T. Kempf, B. Lagerqvist et al., "Growthdifferentiation factor-15 for long-term risk prediction in patients stabilized after an episode of non-ST-segment-elevation acute coronary syndrome," Circulation: Cardiovascular Genetics, vol. 3, no. 1, pp. 89-96, 2010.

[73] L. Lind, L. Wallentin, T. Kempf et al., "Growth-differentiation factor-15 is an independent marker of cardiovascular dysfunction and disease in the elderly: results from the Prospective Investigation of the Vasculature in Uppsala Seniors (PIVUS) Study," European Heart Journal, vol. 30, no. 19, pp. 2346-2353, 2009.

[74] C. Cuspidi, C. Sala, F. Negri, G. Mancia, and A. Morganti, "Prevalence of left-ventricular hypertrophy in hypertension: an updated review of echocardiographic studies," Journal of Human Hypertension, vol. 26, no. 6, pp. 343-349, 2012.

[75] A. V. Chobanian, G. L. Bakris, H. R. Black et al., "The seventh report of the joint national committee on prevention, detection, evaluation, and treatment of high blood pressure: the JNC 7 report," Journal of the American Medical Association, vol. 289, no. 19, pp. 2560-2572, 2003.

[76] S. Zhan, M. Liu, W. Yao et al., "Prevalence and relevant factors on echocardiographic left ventricular hypertrophy among community-based hypertensive patients in Shanghai," 
Zhonghua Liu Xing Bing Xue Za Zhi, vol. 23, no. 3, pp. 182-185, 2002.

[77] D. Levy, R. J. Garrison, D. D. Savage, W. B. Kannel, and W. P. Castelli, "Prognostic implications of echocardiographically determined left ventricular mass in the Framingham Heart Study," The New England Journal of Medicine, vol. 322, no. 22, pp. 1561-1566, 1990.

[78] G. Schillaci, P. Verdecchia, C. Porcellati, O. Cuccurullo, C. Cosco, and F. Perticone, "Continuous relation between left ventricular mass and cardiovascular risk in essential hypertension," Hypertension, vol. 35, no. 2, pp. 580-586, 2000.

[79] X. Y. Xu, Y. Nie, F. F. Wang et al., "Growth differentiation factor (GDF)-15 blocks norepinephrine induced myocardial hypertrophy via a novel pathway involving inhibition of epidermal growth factor receptor transactivation," The Journal of Biological Chemistry, vol. 289, no. 14, pp. 10084-10094, 2014.

[80] S. Hanatani, Y. Izumiya, S. Takashio et al., "Growth differentiation factor 15 can distinguish between hypertrophic cardiomyopathy and hypertensive hearts," Heart and Vessels, vol. 29, no. 2, pp. 231-237, 2014.

[81] O. F. Bueno and J. D. Molkentin, "Involvement of extracellular signal-regulated kinases $1 / 2$ in cardiac hypertrophy and cell death," Circulation Research, vol. 91, no. 9, pp. 776-781, 2002.

[82] R. Derynck and Y. E. Zhang, "Smad-dependent and Smadindependent pathways in TGF-beta family signalling," Nature, vol. 425, no. 6958, pp. 577-584, 2003.

[83] J. Heger, E. Schiegnitz, D. Von Waldthausen, M. M. Anwar, H. M. Piper, and G. Euler, "Growth differentiation factor 15 acts anti-apoptotic and pro-hypertrophic in adult cardiomyocytes," Journal of Cellular Physiology, vol. 224, no. 1, pp. 120-126, 2010.

[84] R. Stahrenberg, F. Edelmann, M. Mende et al., "The novel biomarker growth differentiation factor 15 in heart failure with normal ejection fraction," European Journal of Heart Failure, vol. 12, no. 12, pp. 1309-1316, 2010.

[85] B. Chen, D. Lu, Y. Fu et al., "Olmesartan prevents cardiac rupture in mice with myocardial infarction by modulating growth differentiation factor 15 and p53," British Journal of Pharmacology, vol. 171, no. 15, pp. 3741-3753, 2014.

[86] D. Frank, C. Kuhn, B. Brors et al., "Gene expression pattern in biomechanically stretched cardiomyocytes: evidence for a stretch-specific gene program," Hypertension, vol. 51, no. 2, pp. 309-318, 2008.

[87] G. A. Bonaterra, S. Zügel, J. Thogersen et al., "Growth differentiation factor-15 deficiency inhibits atherosclerosis progression by regulating interleukin-6-dependent inflammatory response to vascular injury," Journal of the American Heart Association, vol. 1, no. 6, Article ID e002550, 2012.

[88] S. Lamouille, C. Mallet, J.-J. Felge, and S. Bailly, "Activin receptor-like kinase 1 is implicated in the maturation phase of angiogenesis," Blood, vol. 100, no. 13, pp. 4495-4501, 2002.

[89] P. Secchiero, F. Corallini, A. Gonelli et al., "Antiangiogenic activity of the MDM2 antagonist nutlin-3," Circulation Research, vol. 100, no. 1, pp. 61-69, 2007.

[90] S. J. Huh, C. Y. Chung, A. Sharma, and G. P. Robertson, "Macrophage inhibitory cytokine-1 regulates melanoma vascular development," The American Journal of Pathology, vol. 176, no. 6, pp. 2948-2957, 2010.

[91] J. N. Topper, "TGF-beta in the cardiovascular system: Molecular mechanisms of a context-specific growth factor," Trends in Cardiovascular Medicine, vol. 10, no. 3, pp. 132-137, 2000.
[92] S. Czernichow and S. Hercberg, "Interventional studies concerning the role of antioxidant vitamins in cardiovascular diseases: a review," The Journal of Nutrition, Health \& Aging, vol. 5, no. 3, pp. 188-195, 2001.

[93] H. Tashiro, H. Shimokawa, K. Yamamoto, M. Momohara, H. Tada, and A. Takeshita, "Altered plasma levels of cytokines in patients with ischemic heart disease," Coronary Artery Disease, vol. 8, no. 3-4, pp. 143-147, 1997.

[94] A. Bobik, A. Agrotis, P. Kanellakis et al., "Distinct patterns of transforming growth factor-beta isoform and receptor expression in human atherosclerotic lesions: colocalization implicates TGF- beta in fibrofatty lesion development," Circulation, vol. 99, no. 22, pp. 2883-2891, 1999.

[95] R. Hutter, C. Valdiviezo, B. V. Sauter et al., "Caspase-3 and tissue factor expression in lipid-rich plaque macrophages: evidence for apoptosis as link between inflammation and atherothrombosis," Circulation, vol. 109, no. 16, pp. 2001-2008, 2004.

[96] E. S. Wintergerst, J. Jelk, C. Rahner, and R. Asmis, "Apoptosis induced by oxidized low density lipoprotein in human monocyte-derived macrophages involves CD36 and activation of caspase-3," European Journal of Biochemistry, vol. 267, no. 19, pp. 6050-6059, 2000.

[97] R. Kinscherf, H.-P. Deigner, C. Usinger et al., "Induction of mitochondrial manganese superoxide dismutase in macrophages by oxidized LDL-its relevance in atherosclerosis of humans and heritable hyperlipidemic rabbits," The FASEB Journal, vol. 11, no. 14, pp. 1317-1328, 1997.

[98] R. Kinscherf, R. Claus, M. Wagner et al., "Apoptosis caused by oxidized LDL is manganese superoxide dismutase and p53 dependent," FASEB Journal, vol. 12, no. 6, pp. 461-467, 1998.

[99] C. Ihling, G. Menzel, E. Wellens, J. S. Monting, H. E. Schaefer, and A. M. Zeiher, "Topographical association between the cyclin-dependent kinases inhibitor P21, p53 accumulation, and cellular proliferation in human atherosclerotic tissue," Arteriosclerosis, Thrombosis, and Vascular Biology, vol. 17, no. 10, pp. 2218-2224, 1997.

[100] Z. Mallat, J. Ohan, G. Lesèche, and A. Tedgui, "Colocalization of CPP-32 with apoptotic cells in human atherosclerotic plaques," Circulation, vol. 96, no. 2, pp. 424-428, 1997.

[101] S. Jovinge, M. P. S. Ares, B. Kallin, and J. Nilsson, "Human monocytes/macrophages release TNF-alpha in response to OxLDL," Arteriosclerosis, Thrombosis, and Vascular Biology, vol. 16, no. 12, pp. 1573-1579, 1997.

[102] R. Kinscherf, R. Claus, H. P. Deigner et al., "Modified low density lipoprotein delivers substrate for ceramide formation and stimulates the sphingomyelin-ceramide pathway in human macrophages," FEBS Letters, vol. 405, no. 1, pp. 55-59, 1997.

[103] R. Kinscherf, M. Wagner, H. Kamencic et al., "Characterization of apoptotic macrophages in atheromatous tissue of humans and heritable hyperlipidemic rabbits," Atherosclerosis, vol. 144, no. 1, pp. 33-39, 1999.

[104] S. C. A. De Jager, B. Bermúdez, I. Bot et al., "Growth differentiation factor 15 deficiency protects against atherosclerosis by attenuating CCR2-mediated macrophage chemotaxis," Journal of Experimental Medicine, vol. 208, no. 2, pp. 217-225, 2011.

[105] T. Kempf and K. C. Wollert, "Growth differentiation factor-15: a new biomarker in cardiovascular disease," Herz, vol. 34, no. 8, pp. 594-599, 2009.

[106] S. Allender, P. Scarborough, M. O'Flaherty, and S. Capewell, "Patterns of coronary heart disease mortality over the 20th century in England and Wales: possible plateaus in the rate of decline," BMC Public Health, vol. 8, article 148, 2008. 
[107] T. Kempf, A. Zarbock, C. Widera et al., "GDF-15 is an inhibitor of leukocyte integrin activation required for survival after myocardial infarction in mice," Nature Medicine, vol. 17, no. 5, pp. 581-588, 2011.

[108] J. Berkman and H. Rifkin, "Unilateral nodular diabetic glomerulosclerosis (Kimmelstiel Wilson): report of a case," Metabolism: Clinical and Experimental, vol. 22, no. 5, pp. 715$722,1973$.

[109] R. P. E. van Dokkum, W. B. A. Eijkelkamp, A. C. A. Kluppel et al., "Myocardial infarction enhances progressive renal damage in an experimental model for cardio-renal interaction," Journal of the American Society of Nephrology, vol. 15, no. 12, pp. 31033110, 2004.

[110] A. S. Desai, R. Toto, P. Jarolim et al., "Association between cardiac biomarkers and the development of ESRD in patients with type 2 diabetes mellitus, anemia, and CKD," American Journal of Kidney Diseases, vol. 58, no. 5, pp. 717-728, 2011.

[111] J. E. Ho, S. J. Hwang, K. C. Wollert et al., "Biomarkers of cardiovascular stress and incident chronic kidney disease," Clinical Chemistry, vol. 59, no. 11, pp. 1613-1620, 2013.

[112] T. A. Zimmers, X. Jin, E. C. Hsiao, S. A. McGrath, A. F. Esquela, and L. G. Koniaris, "Growth differentiation factor15/macrophage inhibitory cytokine-1 induction after kidney and lung injury," Shock, vol. 23, no. 6, pp. 543-548, 2005.

[113] J. P. D. van Huyen, L. Cheval, M. Bloch-Faure et al., "GDF15 triggers homeostatic proliferation of acid-secreting collecting duct cells," Journal of the American Society of Nephrology, vol. 19, no. 10, pp. 1965-1974, 2008.

[114] M. S. Simonson, M. Tiktin, S. M. Debanne et al., "The renal transcriptome of $\mathrm{db} / \mathrm{db}$ mice identifies putative urinary biomarker proteins in patients with type 2 diabetes: a pilot study," The American Journal of Physiology - Renal Physiology, vol. 302, no. 7, pp. F820-F829, 2012.

[115] A. D. Hingorani, J. Cross, R. K. Kharbanda et al., "Acute systemic inflammation impairs endothelium-dependent dilatation in humans," Circulation, vol. 102, no. 9, pp. 994-999, 2000.

[116] T. Kempf, S. von Haehling, T. Peter et al., "Prognostic utility of growth differentiation factor-15 in patients with chronic heart failure," Journal of the American College of Cardiology, vol. 50, no. 11, pp. 1054-1060, 2007.

[117] A. Clerk, T. J. Kemp, G. Zoumpoulidou, and P. H. Sugden, "Cardiac myocyte gene expression profiling during $\mathrm{H}_{2} \mathrm{O}_{2}$ induced apoptosis," Physiological Genomics, vol. 29, no. 2, pp. 118-127, 2007.

[118] E.-S. Han, F. L. Muller, V. I. Pérez et al., "The in vivo gene expression signature of oxidative stress," Physiological Genomics, vol. 34, no. 1, pp. 112-126, 2008.

[119] M. Zhang, S. Lu, X. Wu et al., "Multimarker approach for the prediction of cardiovascular events in patients with mild to moderate coronary artery lesions a 3-year follow-up study," International Heart Journal, vol. 53, no. 2, pp. 85-90, 2012.

[120] R. B. Schnabel, A. Schulz, C. M. Messow et al., "Multiple marker approach to risk stratification in patients with stable coronary artery disease," European Heart Journal, vol. 31, no. 24, pp. 30243031, 2010. 


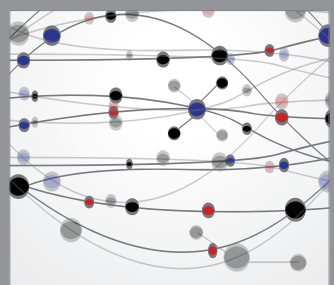

The Scientific World Journal
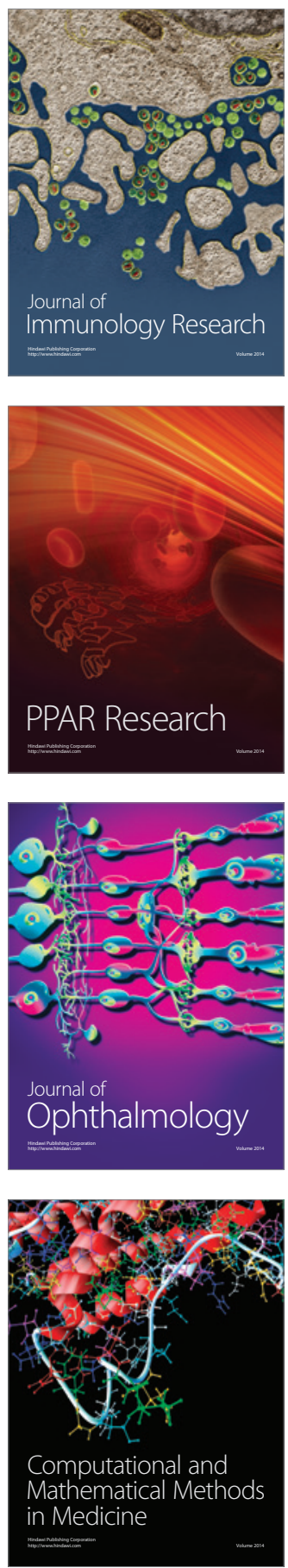

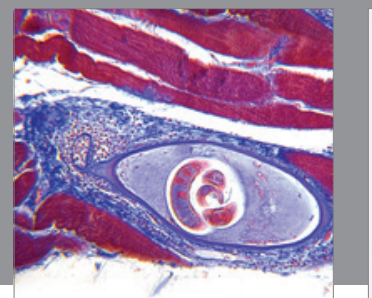

Gastroenterology

Research and Practice
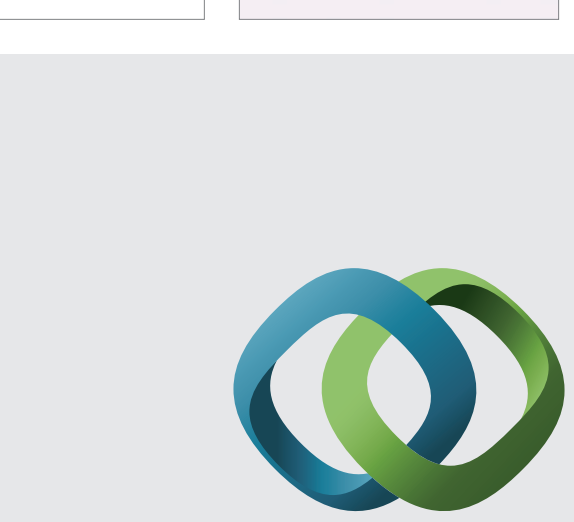

\section{Hindawi}

Submit your manuscripts at

http://www.hindawi.com
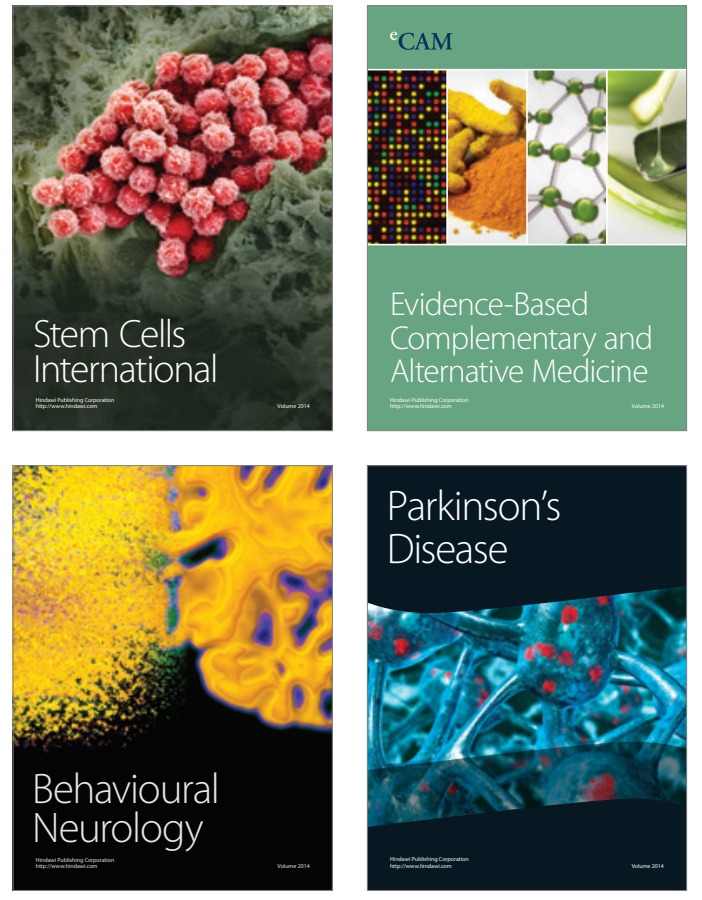
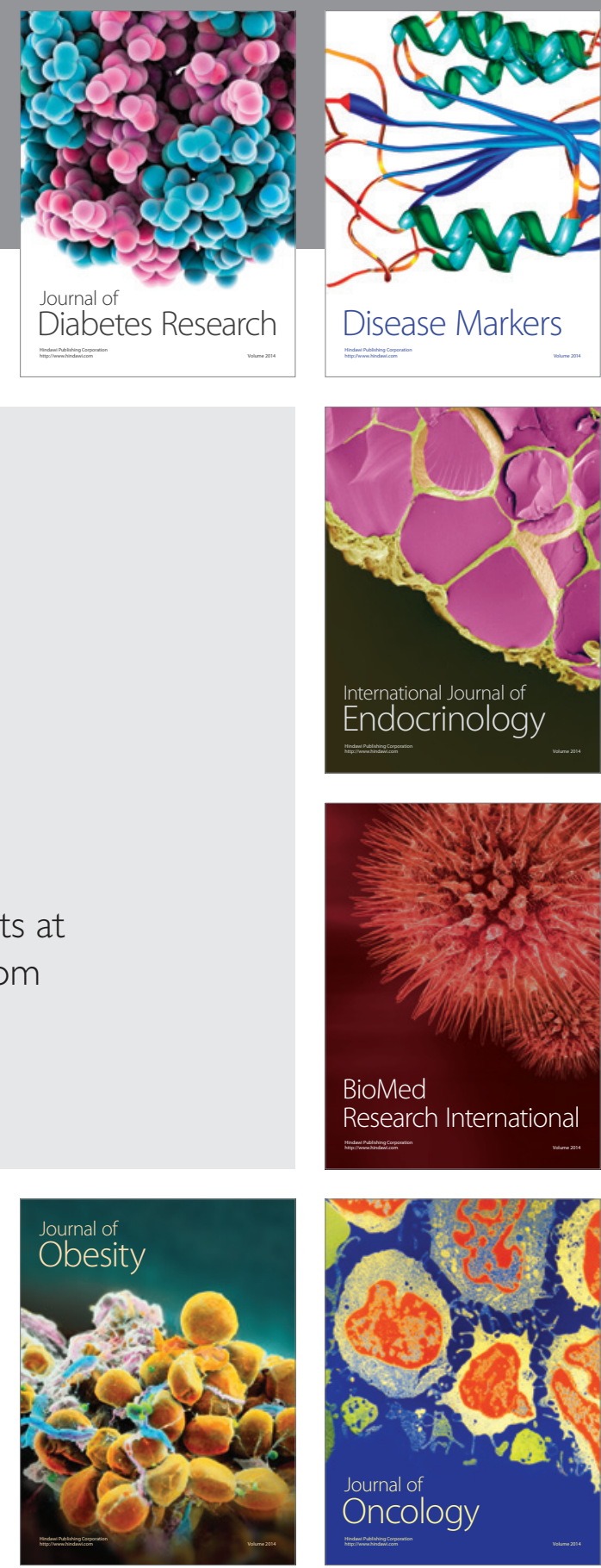

Disease Markers
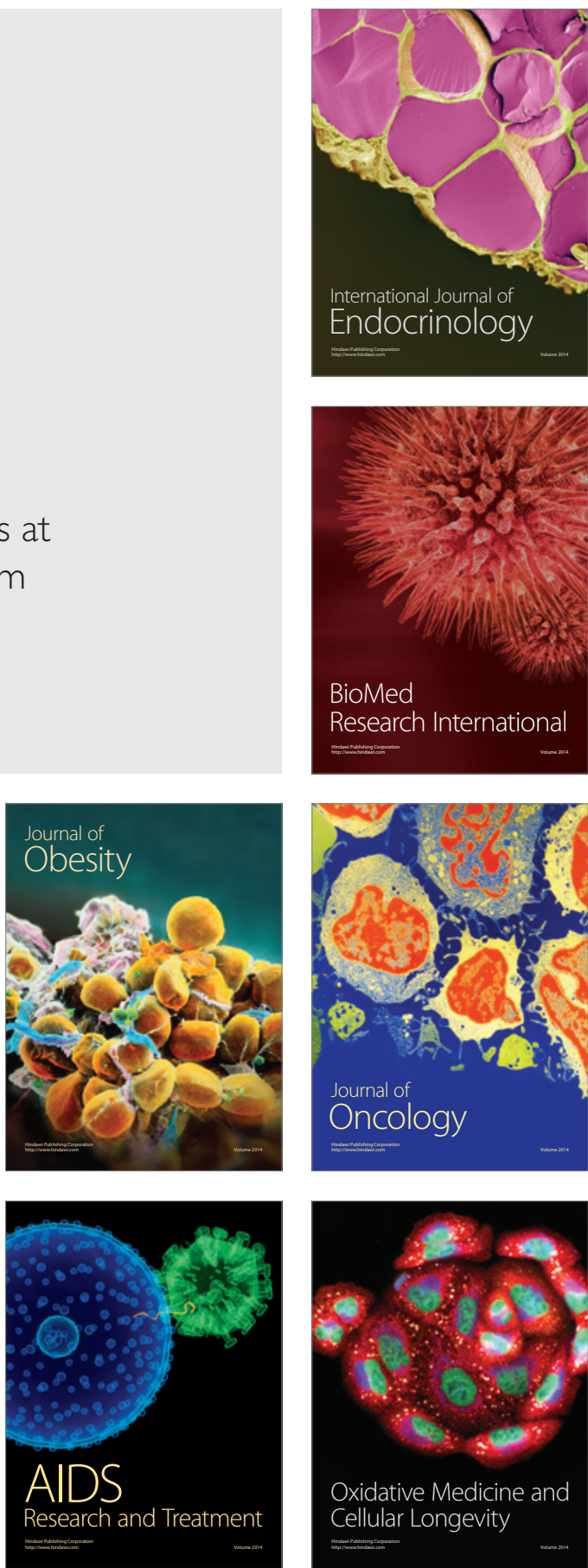